\title{
PENGEMBANGAN TEKNIK MODELING SIMBOLIK UNTUK MENINGKATKAN PERILAKU MENJAGA KELESTARIAN HUTAN KALIMANTAN
}

\section{Development of Symbolic Modeling Techniques to Improve the Behavior of Maintaining the Conservation of Kalimantan Forests}

\section{Mohammad \\ Fatchurahman*}

Karyanti

Universitas Muhammadiyah Palangkaraya, Palangka Raya,

Central Kalimantan, Indonesia

*email: mfatchurahman789@gmail.com

Kata Kunci:
Hutan
Remaja
Modeling simbolik
Keywords:
Forest
Teenagers
Symbolic modeling
Accepted
February 2019
Published
June 2019

\begin{abstract}
Abstrak
Tujuan dari penelitian ini yaitu (I) Untuk mengetahui pelaksanaan teknik modeling simbolik dan gambaran perilaku menjaga kelestarian hutan oleh remaja. (2) Tersusunnya teknik modeling simbolik yang digunakan untuk meningkatkan perilaku menjaga kelestarian hutan. Metode penelitian yang digunakan yaitu Research and Development (R\&D). Research and development atau penelitian pengembangan merupakan salah satu penelitian yang pada akhir penelitian dapat ditemukanya sebuah model baru. Analisis data dilakukan dengan cara kuantitatif dan kualitatif. Hasil dari pengembangan model yang sudah dilakukan peneliti maka tersususnlah sebuah model yang berisi (I) Rasional, (2) Tujuan, (3) Asumsi, (4) Target intervensi, (5) Komponen model, (6) Langkah-langkah model, (7) Materi, (8) Sarana, (9) Evaluasi dan indikator keberhasilan. Model yang sudah tersusun diujicobakan untuk mengetahui tingkat keefektifan dari model yang sudah di susun. Hasil uji coba diketahui bahwa teknik modeling simbolik efektif untuk meningkatkan perilaku menjaga kelestarian hutan. Hal itu berarti ada peningkatan pemahaman tentang perilaku menjaga kelestarian hutan. Oleh karena itu dapat disimpulkan bahwa teknik modeling simbolik efektif untuk meningkatkan perilaku menjaga kelestarian hutan.
\end{abstract}

\begin{abstract}
The objectives of this study are (I) To find out the implementation of symbolic modeling techniques and an overview of the behavior of preserving forests by adolescents. (2) Compilation of symbolic modeling techniques used to improve forest preservation behavior. The research method used is Research and Development (R \& D). Research and development or development research are one of the studies which at the end of the research can be found a new model. Data analysis is done in quantitative and qualitative ways. The results of the model development that have been carried out by the researcher include a model that contains (I) Rational, (2) Objectives, (3) Assumptions, (4) Target interventions, (5) Model components, (6) Model steps, (7) Material, (8) Means, (9) Evaluation and indicators of success. The arranged model is tested to determine the effectiveness of the model that has been arranged. The results of the trial show that symbolic modeling techniques are effective in increasing forest preservation behavior. That means there is an increase in understanding of forest preservation behavior. Therefore, it can be concluded that symbolic modeling techniques are effective in increasing forest preservation behavior.
\end{abstract} Palangkaraya. This is Open Access article under the CC-BY-SA License (http://creativecommons.org/licenses/by-sa/4.0/). DOI: https://doi.org/I0.33084/anterior.v18i2.80I.

\section{PENDAHULUAN}

Hutan penting bagi manusia, hewan dan tumbuhan yang hidup di hutan sangat bergantung pada kelestarian hutan itu sendiri. Siswa cenderung memiliki kepedulian yang rendah terhadap kelestarian hutan, sehingga pemahaman tentang menjaga kelestarian hutan seperti di Kalimantan Tengah perlu ditingkatkan (Hanafi et al., 2017; Maimunah, 2017). Hutan merupakan warisan leluhur yang bernilai tinggi. Kerusakan hutan dapat berdampak negatif bagi masyarakat yang tinggal di sekitar kawasan hutan. Agar tidak terjadi kerusakan hutan, sudah menjadi tugas semua orang, terutama siswa untuk berpartisipasi untuk menjaga kelestarian hutan. Proses pelestarian lingkungan diawali dari adaptasi manusia terhadap lingkungan di mana dia berada (Mustofa, 20I I; Siswanto, 2010). 
Remaja sebagai generasi penerus bangsa sudah seharusnya berperan aktif untuk menjaga kelestarian hutan yang merupakan kearifan lokal suatu daerah. Hutan yang terletak di Kalimantan Tengah perlu dilestarikan agar generasi muda dapat menganal flora dan fauna yang ada di hutan Kalimantan. Bagaimana generasi muda dapat mengenal flora dan fauna, jika hutan yang ada di Kalimantan sebagai kearifan lokal hampir punah. Kerusakan hutan juga berdampak bagi kehidupan manusia. Dampak yang terjadi jika terjadi kerusakan hutan, seperti banjir dan tanah longsor, serta akan terjadi pemanasan global. Hutan penting bagi manusia, hewan dan tumbuhan yang hidup di hutan sangat bergantung pada kelestarian hutan itu sendiri (Niapele, 20/4).

Hutan memiliki banyak fungsi. Bagi manusia, hutan bermanfaat untuk menjaga keseimbangan air tanah. Air tanah sangat diperlukan oleh manusia dalam kehidupan sehari-hari. Hutan bermanfaat bagi kehidupan apabila hutan terjamin eksistensinya sehingga dapat berfungsi secara optimal. Fungsi-fungsi ekologi, ekonomi dan sosial dari hutan akan memberikan peranan nyata apabila pengelolaan sumberdaya alam berupa hutan seiring dengan upaya pelestarian (Ariyadi \& Maimunah, 2017; Nurhadi et al., 2012).

Taufiq (2016) menyatakan bahwa adaptasi merupakan sesuatu yang dilakukan melalui kemampuan organisme (manusia) untuk mengatasi keadaan yang ada pada lingkungannya dan memanfaatkan sumberdaya tersebut sekaligus memeliharanya. Kemampuan untuk mengatasi tersebut dapat dicapai melalui pengaturan dari persyaratan dan toleransi-toleransi terhadap elemenelemen yang terdapat di lingkungan hidupnya. UndangUndang Republik Indonesia Nomor 4I Tahun 1999 tentang Kehutanan pasal I ayat 2 bahwa hutan merupakan kesatuan ekosistem berupa hamparan lahan berisi sumber daya alam hayati yang didominasi pepohonan dalam persekutuan alam lingkungan yang satu dengan lainnya tidak dapat dipisahkan (Akhmaddhian, 20I3).

Hutan menjadi media hubungan timbal balik antara manusia dan makhluk hidup lainnya dengan faktor-faktor alam yang terdiri dari proses ekologi dan merupakan suatu kesatuan siklus yang dapat mendukung kehidupan (Niapele, 20I4). Upaya untuk mengembangkan perilaku menjaga kelestarian hutan oleh remaja dapat dilakukan di lingkungan sekolah. Guru Bimbingan dan Konseling dapat melaksanakan strategi layanan bimbingan dan konseling bersama dengan pihak yang terkait dengan pelestarian hutan. Berbagai layanan bimbingan dan konseling telah dilaksanakan oleh guru BK dengan berbagai teknik. Namun, guru BK belum melaksanakan layanan bimbingan konseling dengan teknik modeling simbolik untuk meningkatkan perilaku menjaga kelestarian hutan (Damayatanti, 20I I).

Modeling merupakan teknik untuk mengajari si pengamat keterampilan dan aturan perilaku. Dalam modeling, perilaku orang yang dijadikan model dapat berfungsi sebagai pengingat atau isyarat bagi orang yang mengamatinya (Sutanti, 2017). Pembentukan perilaku dengan teknik modeling dapat dibagi menjadi tiga. Pertama adalah modeling nyata. Modeling nyata adalah model yang dapat ditemukan oleh remaja secara nyata dalam kehidupan sehari hari sehingga anak dapat mengamati secara langsung bahkan berinteraksi dengan model tersebut. Kedua adalah model simbolik. Model simbolik adalah model yang menggunakan simbolsimbol. Disediakan melalui material tertulis seperti gambar, video, film, rekaman audio. Simbol-simbol dari berbagai media tersebut akan menerangkan aspek-aspek dunia nyata sehingga remaja mudah untuk memahaminya. Ketiga adalah modeling ganda. Modeling ganda yang dimaksud adalah menggunakan dua model yakni model nyata dan model simbolik. Teknik modeling ganda dilakukan dengan cara berkelompok (Repita et al., 2016). Berdasarkan uraian diatas maka untuk meningkatkan perilaku menjaga kelestarian hutan pada 
remaja di layanan bimbingan klasikal dengan teknik modeling simbolik, sehingga peneliti mengambil judul Pengembangan Layanan Bimbingan Klasikal dengan Teknik Modeling Simbolik Untuk Meningkatkan Perilaku Menjaga Kelestarian Hutan Kalimantan

\section{METODOLOGI}

Metode penelitian ini menggunakan pendekatan penelitian dan pengembangan. Langkah-langkah yang dalam penelitian pengembangan meliputi: (I) studi pendahuluan, (2) perencanaan, (3) pengembangan model hipotetik, (4) penelaahan model hipotetik, (5) revisi, (6) uji coba terbatas, (7) revisi hasil uji coba, (8) uji coba lebih luas, (9) revisi model akhir, dan (10) diseminasi dan sosialisasi (Sugiyono, 2010). Namun dalam penelitian ini kesepuluh tahapan tersebut dikurangi menjadi enam tahapan, disesuaikan dengan kebutuhan penelitian. Keenam tahapan yang dimaksud dijelaskan dalam prosedur pengembangan. Rancangan pengembangan model tersebut, secara lebih sistematis dapat digambarkan melalui bagan tahap penelitian di bawah ini: studi pendahuluan, merumuskan model hipotetik, perbaikan model hipotetik, uji kelayakan model hipotetik, uji efektifitas, tersusun model akhir.

\section{HASIL DAN PEMBAHASAN}

Model layanan bimbingan klasikal dengan teknik modeling simbolik ini dikembangkan berdasarkan analisis panduan antara temuan empiris di lapangan (yakni kondisi objektif pelaksanaan layanan bimbingan klasikal yang masih belum memanfaatkan teknik modeling simbolik dengan adanya perilaku menjaga kelestarian hutan Kalimantan di kalangan remaja yang masih rendah. Dari teori yang sudah dikembangkan diatas maka model hipotetik tersusun dan terdiri atas beberapa komponen yaitu: (1) Rasional, (2) Tujuan, (3) Asumsi, (4) Target intervensi, (5) Komponen model, (6) Langkah-langkah model, (7) Materi, (8) Sarana, (9) Evaluasi dan indikator keberhasilan.
Berikut ini sajian perbandingan hasil pengukuran tingkat perilaku menjaga kelestarian hutan dengan menggunakan skala perilaku menjaga kelestarian untuk meningkatkan perilaku menjaga kelestarian hutan remaja saat pre-test dan post-tes pada subjek penelitian. Data hasil pre-test dan post-test pada sujek penelitian dilengkapi dengan terapeutik dalam perubahan diri remaja dari masing-masing remaja pada subjek dan berikut adalah hasil pre-test dan post-test subjek Penelitian. Secara kuantitatif peningkatan menjaga kelestarian hutan bisa dilihat dari perbandingan nilai pretest dan Posttest yang diperoleh masing-masing peserta sebagaimana ditampilkan pada Tabel I.

Tabel I. Perolehan Skor Total Pretest dan Posttest Perilaku Menjaga Kelestarian Hutan Kalimantan

\begin{tabular}{ccccc}
\hline Nama & Pretest & Kategori & Posttes & Kategori \\
\hline NR & 96 & Tinggi & 102 & Tinggi \\
SH & 94 & Tinggi & 95 & Tinggi \\
RA & 91 & Tinggi & 93 & Tinggi \\
AD & 72 & Sedang & 97 & Tinggi \\
FA & 69 & Sedang & 98 & Tinggi \\
RI & 69 & Sedang & 95 & Tinggi \\
RE & 65 & Sedang & 96 & Tinggi \\
FS & 64 & Sedang & 97 & Tinggi \\
AN & 63 & Sedang & 94 & Tinggi \\
RK & 62 & Sedang & 93 & Tinggi \\
AM & 62 & Sedang & 96 & Tinggi \\
HM & 59 & Sedang & 99 & Tinggi \\
AR & 48 & Rendah & 99 & Tinggi \\
RN & 47 & Rendah & 99 & Tinggi \\
RK & 44 & Rendah & 104 & Tinggi \\
BN & 43 & Rendah & 102 & Tinggi \\
MZ & 43 & Rendah & 100 & Tinggi \\
AA & 42 & Rendah & 89 & Tinggi \\
NN & 42 & Rendah & 92 & Tinggi \\
MY & 42 & Rendah & 97 & Tinggi \\
NA & 42 & Rendah & 94 & Tinggi \\
SR & 41 & Rendah & 76 & Sedang \\
RH & 41 & Rendah & 62 & Sedang \\
MH & 39 & Rendah & 95 & Tinggi \\
MA & 39 & Rendah & 69 & Sedang \\
KB & 43 & Rendah & 62 & Sedang \\
\hline & & & & \\
\hline
\end{tabular}




\begin{tabular}{lllll}
\hline AS & $4 I$ & Rendah & 92 & Tinggi \\
\hline
\end{tabular}

Visualisasi Tabel I dalam bentuk grafik sebagaimana dapat dilihat pada Gambar I berikut ini:

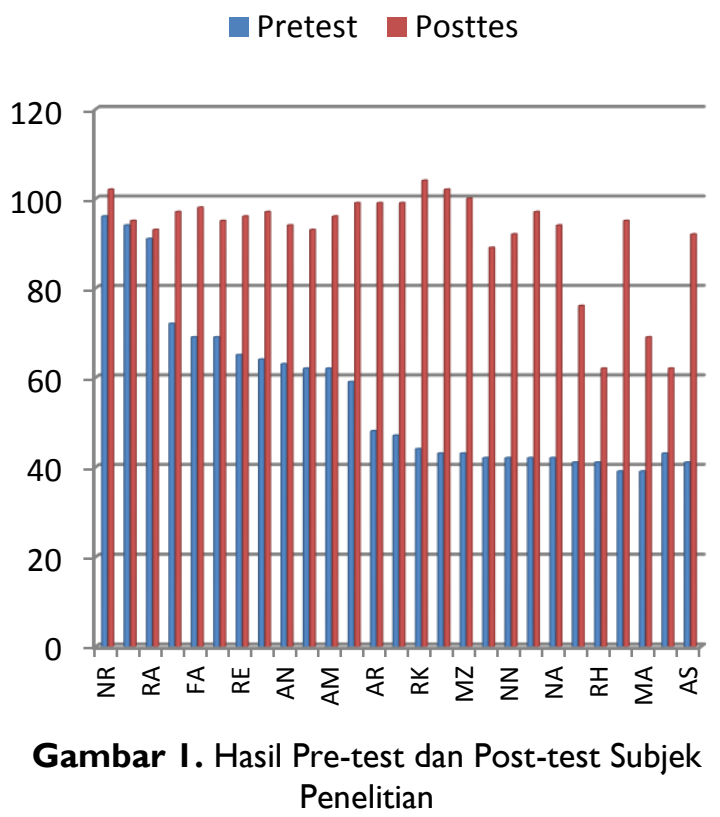

Berdasarkan Gambar I di atas terlihat bahwasanya perilaku menjaga kelestarian hutan pada semua peserta yang menjadi anggota bimbingan klasikal mengalami peningkatan (nilai posttest lebih tinggi dari nilai pretetst). Ketercapaian hasil tersebut karena teknik modeling simbolik yang dilaksanakan dilaksanakan secara profesional sesuai dengan prosedur yang telah direncanakan. Berdasarkan tabel diatas dapat diketahui bahwa perilaku menjaga kelestarian hutan mengalami peningkatan. Sejumlah subjek penelitian yang berjumlah 27 orang, terdapat tiga peserta yang mengalami peningkatan perilaku menjaga kelestarian hutan tidak terlalu signifikan yaitu AN, RK dan RA, ketiga peserta tersebut pada tahap preetes. Berada pada kategi tingi dan di tahap posttes mengalami peningkatan nilai namun tidak ada peningkatan kategiri. Sebelas peserta yang lain mengalami peningkatan yang signifikan yang berdampak pada perubahan kategori yaitu AR, RN, RK, BN, MZ, AA, NN, MY, NA, MH dan AS mengalami perubahan kategori, pada tahap preetes ke sebelas peserta tersebut berada pada kategori rendah dan pada saat posttes mengalami peningkatan kategori menjadi tinggi. Terdapat tiga belas peserta didik yang mengalami peningkatan sedang, karena terjadi peningkatan satu kategori yaitu AD, FA, RI, RE, FS, AN, RK, AM, HM, SR, $\mathrm{RH}, \mathrm{MA}$, dan KB Kondisi tersebut terjadi karena peserta belum bisa menemukan solusi yang paling efektif dari setiap permasalahan yang dihadapi khususnya terkait perilaku menjaga kelestarian hutan.

\section{KESIMPULAN}

Berdasarkan hasil analisis data, mulai dari tahap penelitian pendahuluan sampai pada uji coba model dapat dirumuskan simpulan yaitu telah ditemukan desain teknik modeling simbolik untuk meningkatkan perilaku menjaga kelestarian hutan Kalimantan. Teknik modeling simbolik efektif dapat meningkatkan perilaku menjaga kelestarian hutan Kalimantan setelah dilakukan uji coba kepada Kelompok eksperimen. Oleh karena itu dapat disimpulkan bahwa teknik modeling simbolik efektif untuk meningkatkan perilaku menjaga kelestarian hutan.

\section{REFERENSI}

Akhmaddhian, S., 2013. Peran Pemerintah Daerah dalam Mewujudkan Hutan Konservasi Berdasarkan Undang-undang Nomor 4I tahun 1999 tentang Kehutanan (Studi di Kabupaten Kuningan). Jurnal Dinamika Hukum, I3, 446-456.

Ariyadi, A., \& Maimunah, S. 2017. Peran Agama Islam dalam Konservasi Hutan. Daun: Jurnal Ilmiah Pertanian Dan Kehutanan, 4, 63-74.

Damayatanti, P.T. 20II. Upaya Pelestarian Hutan Melalui Pengelolaan Sumberdaya Hutan Bersama Masyarakat. Komunitas: International Journal of Indonesian Society and Culture, 3, 7082.

Hanafi, N., Fahruni, F., \& Maimunah, S. 2017. Sosialisasi Pemanfaatan Hasil Hutan Bukan Kayu (HHBK) Sebagai Salah Satu Bentuk Pengelolaan KHDTK Kota Palangka Raya. PengabdianMu: Jurnal Ilmiah Pengabdian Kepada Masyarakat, 2, 3I-36. 
Maimunah, S. 2017. Model Perlindungan Hutan dengan Pendekatan Pemanfaatan HHBK bagi Masyarakat Kawasan Hutan Pendidikan UM Palangkaraya. Daun: Jurnal Ilmiah Pertanian Dan Kehutanan, 4, 100-108.

Mustofa, M.S., 20II. Perilaku masyarakat desa hutan dalam memanfaatkan lahan di bawah tegakan. Komunitas: International Journal of Indonesian Society and Culture, 3, I-I I.

Nurhadi, A., Setiawan, B., \& Baiquni, B., 2012. Kearifan Lingkungan Dalam Perencanaan Dan Pengelolaan Hutan Wonosari Kecamatan Ngawen Kabupaten Gunung Kidul. Jurnal Manusia dan Lingkungan, 19, 226-237.

Niapele, S. 2013. Bentuk Pengelolaan Hutan Dengan Kearifan Lokal Masyarakat Adat Tugutil. Agrikan: Jurnal Agribisnis Perikanan, 6, 62-72.

Repita, L.E., Parmiti, D.P., \& Tirtayani, L.A. 2016. Implementasi Teknik Modeling Untuk Meminimalisasi Perilaku Bermasalah Oppositional Defiant Pada Anak Kelompok B. Jurnal Pendidikan Anak Usia Dini Undiksha, 4, I12.

Sarah, S., Gading, K.I., \& Lestari, L.P.S. 2016. Efektivitas Konseling Behavioral Dengan Teknik Modeling Simbolik Dan Teknik Disensitisasi Sistematis Untuk Meningkatkan Efikasi Diri Akademik Siswa Kelas X Tata Kecantikan Smk Negeri 2 Singaraja Tahun Pelajaran 2015/2016. Jurnal Ilmiah Bimbingan Konseling Undiksha, 4, I-I0.

Siswanto, H. 2010. Pengaruh Metode Pembelajaran dan Persepsi Tentang Lingkungan terhadap Kepedulian Taruna Pada Pelestarian Laut (Eksperimen pada Taruna Sekolah Tinggi Ilmu Pelayaran, Jakarta). Jurnal Ilmiah Pendidikan Lingkungan dan Pembangunan, II, 49-70.

Sugiyono. 2010. Metode Penelitian Pendidikan (Pendekatan Kuantitatif, Kualitatif dan R\&D. Bandung: Alfabeta.

Sutanti, T. 2017. Bimbingan Klasikal Dengan Teknik Simbolik Model Sebagai Alternatif Solusi Untuk Meningkatkan Empati Pada Anak Usia Dini. Prosiding Seminar Bimbingan dan Konseling, I, 369- 380.

Taufiq, A., 2016. Upaya Pemeliharaan Lingkungan Oleh Masyarakat Di Kampung Sukadaya Kabupaten Subang. Jurnal Geografi GEA, I4, I24-I34.

Undang-Undang Republik Indonesia Nomor 4I Tahun 1999 tentang Kehutanan. 